\title{
Contextos e significados das ações afirmativas no ensino superior brasileiro: aspectos sociojurídicos e a desconstrução do pacto de silêncio'
}

\author{
Priscila Martins Medeiros \\ Doutoranda em Sociologia (Universidade Federal de São Carlos) \\ São Carlos, Brasil \\ medeiros.ufscar@gmail.com
}

\begin{abstract}
Resumo 0 novo cenário inaugurado com as primeiras experiências de políticas de ação afirmativa no ensino superior brasileiro trouxe uma série de disputas jurídicas entre o Estado, as instituições de ensino superior e os indivíduos que se sentiram lesados por tais políticas, além de colocar no centro da agenda nacional a possibilidade de uma revisão dos princípios democrático-liberais e dos mecanismos de justiça social utilizados no país. Diante desse quadro, realizamos uma pesquisa que teve como objetivo oferecer uma análise sociológica das repercussões no campo jurídico brasileiro pela adoção das ações afirmativas no ensino superior, voltadas principalmente para a população negra, a fim de percebermos as representações de sociedade presentes nos discursos e os posicionamentos do Poder Judiciário e de parte dos estudantes que acionaram a justiça contra essas medidas. Constituíram fontes primárias da pesquisa os acórdãos disponibilizados nos sites dos tribunais de justiça regionais e estaduais, instrumentos legais e al gumas entrevistas. A defesa da mestiçagem como um elemento fundador de igualdade entre os sujeitos e 0 valor do mérito individual são alguns dos pontos que caracterizam esses discursos aqui analisados.
\end{abstract}

Palavras-chave: ações afirmativas; universidades; campo jurídico; igualdade; mérito.

\section{Contextos e significados}

$\Lambda$ SRELAÇÕES RACIAIS SÃO CENTR AIS para compreender a formação da sociedade brasileira e das desigualdades presentes em todas as efferas da vida social. Essa é uma constatação pautada não somente pela observação histórica, mas sobretudo pelo olhar sociológico da real idade do país, iniciado com obras fundamentais dos anos 30 s do século XX e chegando aos dias atuais a uma gama imensa de estudos

1 Este artigo é um desdobramento da dissertação de mestrado intitulada Raça e Estado democrático: o debate sociojurídico acerca das políticas de ação afirmativa no Brasil, defendida em março de 2009 no Programa de Pós-Graduação em Sociologia da Universidade Federal de São Carlos (PPGS/UFSCar). A pesquisa contou com o financiamento da Fundação de Apoio à Pesquisa do Estado de São Paulo (Fapesp). 
que relatam a condição do negro no B rasil2 e que também já apontam os resultados dos primeiros sete anos de políticas de ação afirmativa voltadas para a população negra no acesso ao ensino superior ${ }^{3}$.

0 surgimento das políticas de ação afirmativa no Brasil se dá de forma bastante singular: enquanto nos Estados U nidos, por exemplo, elas se desenvolveram com a aprovação e o respaldo estatais, no Brasil, o movimento negro não esperou pelo lento processo de discussão e aprovação de tais medidas por parte do Estado brasilei ro. Aqui, as ações afirmativas já são aplicadas em várias áreas, como na educação, como iniciativas diretas do movimento social que impulsionaram as universidades ou legislativos estaduais e municipais para a aprovação e a efetivação dessas políticas. Esse processo é acompanhado por contestações jurídicas, pois o Poder Judiciário ainda discute a possibilidade constitucional de tais medidas, porém, o momento atual é marcado pela presença de projetos que estão em votação no C ongresso $\mathrm{N}$ acional ${ }^{4}$ e que podem inaugurar um novo capítulo no tratamento das questões raciais no país.

0 aumento do nível de aprovação das ações afirmativas ${ }^{5}$ é o reflexo de um desdobramento que vem acontecendo no debate sobre relações raciais, no qual estão o movimento negro, cientistas sociais e o Estado brasileiro, este que aos poucos vem agregando as reivindicações na pauta das políticas públicas. No primeiro movimento desse desdobramento, observamos, de um lado, uma série de ações do movimento negro, principalmente a partir da Constituinte de 1987 - com as reivindicações e propostas levadas para a Subcomissão dos N egros, Populações I ndígenas, Pessoas D eficientes e M inorias - e, de outro, várias ações do Estado, desde a criação do Grupo Interministerial de Valorização da População N egra (GTI População N egra), em 1995.

Em um segundo movimento, vemos o ressurgimento de alguns temas, como democracia racial ${ }^{6} \mathrm{e}$ igualdade racial, que vêm marcar um novo cenário nos debates acadêmicos sobre a questão. 0 aumento de medidas - mesmo que em caráter de programas adotadas pelo Estado, o fortalecimento da atuação do movimento negro e 0 acirramento do debate entre os acadêmicos dos "temas ressurgidos", tudo isso em conjunto forçou um terceiro desdobramento, que desloca as discussões sobre as ações afirmativas do campo político também para o campo jurídico ${ }^{7}$. Exemplos não

2 Os primeiros anos do século XX são especialmente importantes para compreendermos o desenvolvimento de discursos racistas que permaneceram do decorrer de todo o século, porém sempre com novas roupagens. Para a compreensão desses discursos, é imprescindível a leitura da obra Casa grande \& senzala, de Gilberto Freyre, que ainda hoje é muito citada, seja para apontar seu ineditismo na discussão sobre o regime escravista e as relações raciais no Brasil, seja para discutir sobre suas limitações em romper com os discursos biologizantes e com os estereótipos da época, tais como os proferidos por Oliveira Vianna e Nina Rodrigues. A literatura brasileira sobre as relações raciais seguiu por diferentes caminhos, desde as perspectivas de cunho redistributivo, até aquelas por vezes citadas como saberes subalternos (que faz referência aos trabalhos de Antonio Gramsci), entre os quais estão os estudos pós-coloniais.

3 Ao nosso entender, as ações afirmativas são medidas que visam a mudanças nas mais diversas esferas da vida social, especialmente no que diz respeito aos discursos e às práticas sociais, na defesa de um verdadeiro respeito às diferenças étnico-raciais, de gênero, de nacionalidade, entre outras especificidades. As ações afirmativas podem assumir diversos formatos, desde a reserva de vagas para grupos sociais específicos no mercado de trabalho até a reconfiguração de currículos escolares e de propostas pedagógicas com a utilização de estratégias que desafiem preconceitos e legitimem as vozes daqueles cujos padrões culturais não correspondem aos dominantes. Com relação às modalidades de ação afirmativa adotadas no ensino superior brasileiro, atualmente contamos com 72 instituições de ensino superior, entre universidades, Fatecs e Cefets que já aplicam algum programa de acesso e/ou permanência diferenciados para estudantes de grupos sociais específicos. Fonte: Laboratório de Políticas Públicas - Programa Políticas da Cor, UERJ, 2009

4 O Projeto de Lei 73/1999 (PL das Cotas) propõe reserva mínima de 50\% das vagas nas Ifes e nas escolas técnicas de ensino médio para estudantes oriundos da rede pública de ensino e também com recortes racial e de renda. Essa proposta foi aprovada na Câmara dos Deputados no dia 20 de novembro de 2008 - Dia Nacional da Consciência Negra - e, como o texto sofreu modificações, ele segue para o Senado Federal. Antes disso, no dia 1/7/2008, a Comissão de Educação, Cultura e Esporte aprovou o PL 546/07, que propõe reserva mínima de 50\% das vagas nas IFES e nas instituições federais de educação profissional e tecnológica para alunos que tenham cursado integralmente o ensino fundamental em escolas públicas, em especial para negros, indígenas e pessoas com deficiência (para estes últimos é indiferente o fato de terem cursado o ensino fundamental em escolas públicas ou privadas).

5 Em 1995, o livro Racismo cordial demonstrou que 48\% das pessoas entrevistadas apoiavam as reservas de vagas para negros na educação e no mercado de trabalho. Já em 2006, cinco anos após a Conferência de Durban (África do Sul, setembro de 2001) e das primeiras experiências de reserva de vagas em universidades públicas, o instituto Datafolha registrou que o percentual de aprovação dessas políticas subiu para $65 \%$ (Queiroz \& Santos, 2006: p. 718).

6 Segundo Guimarães, esse termo passou a ser utilizado na literatura acadêmica pela primeira vez por Charles Wagley em 1952, porém existem registros sobre sua utilização por Arthur Ramos e Roger Bastide já durante os anos 40 (Guimarães, 2002, p. 139).

7 Entendo por "campo jurídico brasileiro" o espaço delimitado pelo Poder Judiciário - definido nos Arts. 92 a 126 da Constituição Federal de 1988 - mas também os demais usos da justiça na dinâmica social, como os artigos de juristas que discutem a adoção de políticas de ação afirmativa. O principal foco durante a realização da pesquisa foi a observação das atividades e atribuições específicas do Estado, mas o uso do direito nas demais esferas da sociedade é reflexo do modelo e dos preceitos do Poder Judiciário, o que justifica a importância de observar os espaços para além do contorno estatal. 
faltam para elucidar o surgimento desse novo foco: desde a criação das primeiras experiências de políticas de ação afirmativa no ensino superior, o Judiciário e o M inistério Público têm sido constantemente chamados para avaliar os programas criados pelas universidades através dos casos específicos de pessoas que se sentiram lesadas com as novas medidas que mudam os critérios para o acesso dos alunos. É provável que essas pessoas também percebam que os programas de ação afirmativa adotados por várias universidades brasileiras são um reconhecimento das barreiras sociais existentes no país e dos mecanismos meritocráticos que, décadas após décadas, vêm assegurando a manutenção de espaços sociais segregados racialmente, não só nas universidades públicas, que são freqüentadas por estudantes majoritariamente brancos, mas em toda a estrutura social do país.

A pesquisa documental que realizamos sempre teve como referência as dinâmicas aqui citadas, pois a série de eventos e lutas acumulados no decorrer da história brasileira confere significado às disputas jurídicas e fornece 0 tom dos argumentos utilizados por advogados, juízes e pessoas que não se sentem confortáveis diante dessa conquista que são as ações afirmativas. Esse é o cenário para o qual dirigimos a atenção com o objetivo de encontrar, no interior das argumentações jurídicas, os elementos explicativos do contexto social.

\section{A proposta de análise}

O s documentos foram coletados principalmente dos sites dos tribunais de justiça estaduais e regionais, que disponibilizam os acórdãos sobre estudantes que entraram com pedido de recurso em ações judiciais contra os programas de ação afirmativa adotados por universidades públicas de todo o país. A partir das palavras-captura universidade, vestibular, reserva de vagas e negro, reunimos informações completas sobre 96 ações judiciais movidas contra 14 universidades públicas ${ }^{8}$. As informações foram submetidas a uma análise de conteúdo, iniciada com a categorização dos argumentos levantados pel os estudantes, pelos desembargadores favoráveis e pelos desembargadores contrários aos programas de ação afirmativa. Com isso, chegamos a quatro categorias gerais presentes nos argumentos dos três grupos sociais:

A) A rgumentos constitucionais. São argumentos que fazem referência ao Estado Democrático de Direito e se fundamentam na C onstituição de 1988 e em leis promulgadas nos últimos vinte anos.

B) A rgumentos sobre raça. Estes são os argumentos que se fundamentam em percepções sobre as relações étnico-raciais no Brasil. É neste grupo de argumentos, por exemplo, que se encontram as críticas aos programas de ação afirmativa fundamentadas nas noções de mestiçagem e do mito da democracia racial.

C) A rgumentos sobre educação e sociedade. São argumentos pautados em concepções sobre a formação da sociedade brasileira e suas dinâmicas, sem necessariamente fazer referência direta ao tema das relações étnico-raciais.

D ) A rgumentos burocráticos. São os argumentos relacionados a questões específicas originadas no momento de inscrição ao vestibular ou durante as matrículas.

C ada um desses quatro grandes grupos argumentativos foi dividido em subcategorias que melhor especificam os argumentos de estudantes e desembargadores ${ }^{9}$. Durante todo o trabal ho, construímos uma linha de análise na qual existem muitos elementos: se, de um lado, temos as falas de estudantes e desembargadores, revestidas de argumentos constitucionais, por outro, temos a tentativa da pesquisadora em encontrar no fundamento dessas falas o que de fato esses atores sociais questionam no momento em que criticam os programas de ação afirmativa, ou seja, quais os fundamentos dessas críticas emolduradas por princípios constitucionais. A partir das nossas escolhas teóricas e metodológicas, tivemos a criação de um conjunto de categorias e a descrição de redes argumentativas, que não estavam presentes nas publicações sobre as disputas sociojuridicas em torno das ações afirmativas. $\mathrm{N} \mathrm{a}$

8 As 14 instituições de ensino superior presentes na pesquisa, de acordo com as regiões geográficas e o número de ações judiciais relacionadas a cada uma são: Sul - UFPR (8), UFRGS (7), UEL (6), UFSC (5), UEPG (1), USJ (1); Sudeste - UERJ (49), UFES (2); Norte - UFRA (1); Nordeste - UFBA (5), UFAL (3), UFPE (2), UFRN (1); Centro-Oeste - ESCS (5)

9 Argumentos dos Estudantes: a) igualdade, mérito, razoabilidade, autonomia, direito à educação, jurisprudência desfavorável. b) miscigenação, democracia racial, classe, cópia dos eua. c) excelência acadêmica, políticas universalistas, "populismo". d) comprovação de origem social, critérios não informados, violação de normas anteriores, fraudes durante a ação judicial. Argumentos dos desembargadores favoráveis: a) igualdade material, mérito inabalado, razoabilidade inabalada, autonomia inabalada, direito à educação, jurisprudência favorável, execução legal. b) sociedade discriminatória, história de branqueamento, defesa de ações afirmativas e programas nacionais, criar uma elite negra. c) interesse coletivo, políticas universalistas não bastam, diminuição do elitismo nas universidades. d) nota insuficiente, observância das regras do vestibular, coerência da comissão na definição de raça, manutenção dos recursos das universidades, outros. Argumentos dos desembargadores desfavoráveis: a) igualdade, mérito, razoabilidade, autonomia, direito à educação, jurisprudência desfavorável. b) miscigenação, classe. c) excelência acadêmica, políticas universalistas, interesses coletivos. d) comprovação de origem social, critérios não informados, violação de normas anteriores, coerência da decisão anterior 
anál ise dos dados, compreendemos que os argumentos constitucionais levantados nos documentos sempre acabam se relacionando a alguns argumentos das outras três categorias: sobre raça, sobre educação e sociedade ou burocráticos, formando redes argumentativas. A característica central das redes é que os argumentos sempre se iniciam com elementos constitucionais que se desdobram em justificativas e exemplos pautados em outros elementos argumentativos, que elucidam as perspectivas e representações de sociedade presentes nos discursos sobre as ações afirmativas.

Em um primeiro olhar sobre os dados levantados durante a pesquisa já constatamos qual é o maior foco das resistências às ações afirmativas: o recorte étnicoracial. To das as universidades so bre as quais foi encontrado um número reduzido de ações judiciais (U FES, U SI, U FR A e U FR N ) não têm ações afirmativas com esse recorte ${ }^{10}$. A lém disso, ao lermos os argumentos dos estudantes nas ações judiciais movidas contra os programas que não exibem recorte étnico-racial, vemosque, além de não existir nenhum argumento fundamentado na noção de raça (até porque não é o caso dessas universidades), também não foi utilizado nenhum outro argumento diretamente pautado em percepções sobre os problemas percebidos na sociedade brasileira ou em críticas aos supostos problemas sociais e educacionais que as ações afirmativas causariam. I sso pode indicar que, para esses estudantes, se não existe 0 "problema do recorte étnico-racial", também não existem razões para contestar os programas pautados somente em critérios socioeconômicos.

A pesar do significativo número de ações judiciais movidas contra os programas de ação afirmativa no ensino superior, vemos que, de maneira geral, os tribunais de justiça têm apresentado sentenças finais favoráveis às universidades que adotam tais medidas. Entre todos os casos coletados na pesquisa, 68,75\% deles tiveram desfecho com ganho de causa das instituições de ensino superior. Vale a pena observar que, apesar do esforço realizado pela mídia em desqualificar os programas de ação afirmativa, a U ER ${ }^{11}$, uma das universidades mais citadas nos jornais, teve ganho de causa em quase $80 \%$ das ações judiciais aqui analisadas. 0 fato de as universidades cariocas terem sido palco da primeira experiência de ações afirmativas no ensino superior brasileiro, somado à avalanche de reações conservadoras por parte de uma mídia hegemônica, ajuda-nos a entender 0 grande número de estudantes que se posicionaram contrariamente a esses programas por meio da justiça.

Consideramos, entretanto, que a publicização de posições contrárias às ações afirmativas foi bastante positiva por dois motivos principais: primeiro, porque a massiva divulgação dos conflitos judiciais colocou em evidência a fragilidade do argumento sobre a pretensa existência de uma democracia racial brasileira, e, em segundo lugar, porque o pior inimigo na luta pela desnaturalização das hierarquias sociais é o silêncio, que começa a ser quebrado. Foucault é um autor que buscou realizar uma arqueologia do silêncio, silêncio dos sujeitados e que é o primeiro e mais forte componente dos processos de estigmatização, discriminação e marginalização. Foucault quis compreender como se dão esses processos, que negam ou desfiguram as falas de muitos sujeitos e que operam no nível da percepção social, das instituições sociais, do aparelho judiciário, da família, do Estado e do senso comum (Foucault, 2005; Bruni, 1989). O conjunto de discursos e práticas sociais presentes nessas dimensões formam o que Foucault chama de dispositivo, que é

um conjunto decididamente heterogêneo que engloba discursos, instituições, organizações arquitetônicas, decisões regulamentares, leis, medidas administrativas, enunciados científicos, proposições filosóficas, morais, filantrópicas. Em suma, o dito e o não dito são elementos do dispositivo. 0 dispositivo é a rede que se pode estabelecer entre esses elementos. (Foucault apud M iskolci, 2009)

No Brasil, quando se procura discutir a discriminação racial e a adoção de medidas específicas, tais como as ações afirmativas, uma das primeiras reações contrárias é a defesa de que não se deve falar sobre o racismo, pois isso acirraria os conflitos raciais. Então, busca-se no Brasil a perpetuação de uma espécie de pacto de silêncio estabelecido pelo mito da democracia racial e no qual nenhum dos lados deve se manifestar, ou seja, não se faz a autocrítica sobre as práticas racistas e os sujeitados não devem questionar ou incomodar o racismo estabelecido. 0 exercício do silêncio significa afundar no esquecimento as palavras imperfeitas; é

10 Com exceção da UEPG, que também apresentou pouquíssimas contestações judiciais, mas que estabelece uma pequena reserva de vagas para estudantes negros egressos de escolas públicas (5\% do total das vagas).

11 A UERJ e as demais IES estaduais do Rio de Janeiro (UENF, UEZO, além da FAETEC - RJ) são as primeiras a adotarem programas de ação afirmativa no Brasil, que surgiram a partir de leis estaduais (no total foram aprovadas seis leis: Leis 3.524/2000, 4.061/2001 e 4.061/2003, que mais tarde foram substituídas pela Lei 4.151/2003. Esta foi alterada com a aprovação da Lei 7.054, de 17 de julho de 2007 , que, por sua vez, foi revogada pela Lei 5.346, em 11 de dezembro de 2008). A última das leis estabeleceu novas regras principalmente no que diz respeito à permanência dos estudantes que ingressam nas instituições. A Lei Estadual n. 5.346, de 11/12/2008, reza em seu Art. $3^{\circ}$ que: "É dever do Estado do Rio de Janeiro proporcionar a inclusão social dos estudantes carentes destinatários da ação afirmativa objeto desta Lei, promovendo a sua manutenção básica e preparando seu ingresso no mercado de trabalho, inclusive mediante as seguintes ações: I - pagamento de bolsa-auxílio durante o período do curso universitário; II - reserva proporcional de vagas em estágios na administração direta e indireta estadual; III - instituição de programas específicos de crédito pessoal para instalação de estabelecimentos profissionais ou empresariais de pequeno porte e núcleos de prestação de serviços". 
o rompimento do diálogo e a separação compreendida como algo já adquirido, desde sempre.

\section{A rediscussão de valores da modernidade}

A lguns dos argumentos constitucionais são mais empregados pelos estudantes e aparecem distribuídos em um número maior de universidades: de um lado, estão as universidades que têm programas de ação afirmativa com recorte racial e que apresentam em comum 0 fato de terem recebido críticas relacionadas a questões de igualdade, mérito e autonomia12 e, de outro, estão as universidades com programas voltados apenas para egressos da rede pública e que têm em comum a incidência de críticas fundamentadas nas questões de raz oabilidade ${ }^{13}$, igualdade e autonomia.
A pesar de os resultados serem bastante questionáveis, o que vemos, tanto em algumas literaturas internacionais quanto brasileiras, é um esforço de vários autores no sentido de avaliar o verdadeiro alcance do princípio liberal da igualdade e também seu substrato, suas raízes. A inda que reconheçamos que grande parte dessas literaturas traz novas propostas apenas colocadas sobre um terreno intacto de pressupostos eurocêntricos, percebemos, no âmbito desta pesquisa, que as críticas levantadas pelos estudantes e seus advogados ainda não alcançaram nem mesmo esse patamar do debate e ainda recorrem a concepções de igualdade já questionadas inclusive pelos mais conservadores.

Se antes a igualdade jurídica (ou formal) era um princípio na prática "adormecido" nas linhas constitucionais, pode-se afirmar que ele foi fortemente sacolejado com o debate das ações afirmativas no Brasil, que vêm questionar esta que é uma das mais famosas promessas da modernidade. No caso brasileiro, as ações afirmativas questionam até que ponto as inovações trazidas pela

12 Com relação ao princípio da autonomia, a Constituição brasileira, em seu Artigo 37, determina que a administração pública deve obedecer ao princípio da legalidade e só pode agir quando a lei obriga ou permite. Essa definição é o que difere as ações da administração pública das relações privadas, em que as particularidades podem agir quando a lei não proíbe. Porém, hoje em dia já se sustenta que o administrador público não precisa ter essa relação tão rígida com a lei, podendo agir sem a autorização expressa, mas com a obrigação de se apoiar em princípios constitucionais, tais como o da igualdade (Neto, 2008). No que diz respeito às ações afirmativas no ensino superior, o tema é tratado com menos complexidade, ainda mais porque a própria CF/88 atribui autonomia às universidades em seu artigo 207: "As universidades gozam de autonomia didático-científica, administrativa e de gestão financeira e patrimonial", - "autonomia administrativa" expressa também sua competência em definir o processo seletivo de seus estudantes, respeitados os limites constitucionais. Por essa razão, os tribunais de justiça raramente apresentam resistências quanto a essa questão, apesar dos estudantes e seus advogados apresentarem, insistentemente, críticas relacionadas aos limites da autonomia universitária. Críticas no sentido oposto também ocorrem: no caso das ações afirmativas adotadas pela UERJ, por força de legislação estadual, vários advogados defenderam que, pelo princípio da autonomia universitária, a UERJ poderia decidir em não aplicar a lei, ou alterá-la. Entretanto, os tribunais também têm entendido que, uma vez que o legislador tenha instituído as medidas de ação afirmativa, não cabe à universidade limitá-las. Crítica nesse sentido também foi dirigida por estudante em ação judicial contra a USJ, em Santa Catarina, devido à lei municipal que determinou reserva de $70 \%$ das vagas para egressos do ensino médio público, residentes em São José. Assim como no Rio de Janeiro, o TJ de Santa Catarina defendeu a legislação estabelecida e cumprida pela universidade.

13 No Direito Constitucional brasileiro, o princípio da razoabilidade, também conhecido como princípio de proporcionalidade, diz respeito ao quão compatível é uma lei ou norma aos fins previstos, ou seja, dispõe sobre a relação entre a motivação existente no momento de construção de uma norma e o resultado final, para que os objetivos sejam realmente alcançados e para evitar excessos legais. O princípio da razoabilidade é operacionalizado a partir de três fundamentos básicos, que avaliam a realização das finalidades de acordo com a) a proporcionalidade em si; b) a necessidade e c) a adequação (Neto, 2008). De acordo com o fundamento da proporcionalidade em si, a adoção de uma medida para o atendimento de um princípio constitucional não deve trazer restrições a nenhum outro princípio. Entre os três fundamentos básicos do princípio da razoabilidade, esse é o mais usada nas ações judiciais contra as ações afirmativas e também é o responsável pela maior parte das decisões judiciais que deram ganho de causa aos estudantes. Nesses casos, os tribunais geralmente não negam a validade das ações afirmativas, mas discordam dos percentuais adotados. No tocante ao princípio da razoabilidade de acordo com a necessidade, a Constituição diz que uma medida é justificável se não houver nenhum outro meio menos gravoso para alcançar o mesmo resultado. Os tribunais de justiça entendem que esse princípio é acionado quando, por exemplo, os estudantes criticam as ações afirmativas, dizendo que, no lugar delas deveriam existir mais investimentos nos ensinos fundamental e médio. Nesta pesquisa, quando os estudantes levantavam tal crítica, nós a categorizamos como sendo um argumento sobre educação e sociedade (grupo C, portanto), mais especificamente como uma defesa de políticas universalistas. Já o princípio da razoabilidade com relação à adequação entre meios e fins reza que a reserva de vagas, por exemplo, seja a medida mais adequada para a realização das finalidades pretendidas. Algumas das discussões mais frequentes com relação às ações afirmativas no ensino superior, mais precisamente à reserva de vagas para estudantes egressos de escolas públicas, é que as ações afirmativas seriam inadequadas por não enquadrarem os estudantes que 1) não cursaram integralmente o ensino médio na rede pública; 2) estudam na rede particular mas têm bolsa; 3) são de escolas públicas, mas de colégios federais ou militares; 4) são de escolas públicas situadas em outros Estados da Federação; 5) são estudantes de escolas do tipo SESI ou fundações filantrópicas e que, no entender dos estudantes, deveriam ser considerados na reserva de vagas para estudantes de rede pública. Todos esses tipos de crítica à adequação das reservas de vagas estão presentes nos casos analisados sobre a ESCS, no Distrito Federal. Nesta pesquisa, quando os estudantes levantaram tais críticas, nós as categorizamos como sendo argumentos burocráticos (grupo D, portanto). 
C onstituição brasileira de 1988 possibilitam, de fato, interpretar as demandas atuais e antigas apresentadas pelos movimentos sociais e desenvolvê-las fora da ideologia da democracia racial. I deologia esta que proclama uma dada igualdade entre todos, mas que, na prática, funciona com concepções hegemônicas, eurocentradas e com a redução de populações ao exotismo patrimonial.

A lguns outros argumentos levantados pelos estudantes, como vários daqueles listados no grupo B (argumentos sobre raça), demonstram muito bem como a noção de igualdade é concebida no país da democracia racial. Vejamos um trecho retirado de uma das ações movidas contra a UFBA, na qual o advogado de um estudante defende que não existem barreiras sociais aos negros no Brasil (argumento que se enquadra na subcategoria intitulada por nós como democracia radal):

$0 \mathrm{ra}$, sabe-se que em determinadas áreas do conhecimento humano, como nas artes, musica, esportes, cultura etc, predominam e pontificam, não só no Brasil como nos demais países, como grandes nomes, pessoas de cor negra. $\mathrm{N}$ em por isso se há que imaginar um "sistema de cotas", obrigando a que, nas 'paradas de sucesso', apareçam percentuais pre-estabelecidos de 'músicas de brancos'. N os esportes como o boxe, o futebol, o basquetebol, idem. [...] (mandado de segurança, BA)

No trecho acima percebemos como os argumentos, independentemente se são constitucionais, ou sobre raça, sobre educação e sociedade, ou burocráticos, são relacionados entre si e nos mostram a todo tempo a complexidade do preconceito racial brasileiro, e como ele é expresso no cotidiano a partir dos discursos. A pesar de estarmos vivenciando hoje um momento de desmoronamento do mito da democracia racial, observável em várias efferas da vida social, os casos aqui anali sados nos mostram ainda o peso do mito nas disputas jurídicas e como ele é resgatado sempre que existe a tentativa de romper com as hierarquias socialmente estabelecidas. Em última análise, a igualdade é defendida pelos estudantes no sentido de uma igualdade na mestiçagem.

\section{Discursos da mestiçagem: a frágil carta curinga do racismo}

Entre os estudantes e desembargadores é forte a presença de afirmações com relação a um "Brasil mestiço", o que, segundo eles, seria um dado que des- cartaria imediatamente a necessidade de políticas de ação afirmativa ${ }^{14}$. U m dos principais elementos argumentativos presentes na categoria miscigenação é a afirmação de que seria impossível avaliar quem é negro no país, ainda mais porque a categoria negro seria subjetivamente determinada, o que, segundo os estudantes desta pesquisa, caracterizaria a auto declaração de raça como uma medida fraudulenta. A dificuldade da discussão racial no Brasil é que sempre os discursos são forçados a desaguarem para um sentido técnico, quando, na verdade, o que temos no país é uma situação social complexa e que tem fundamentação sociológica. As formas em que se dão as relações raciais no B rasil e como elas são pensadas se transformaram em um patrimônio nacional imaterial, formado por uma mistura de dois ingredientes chave: a defesa de inexistência do racismo ou preconceito racial no país e, por outro lado, a permanência, no imaginário social, da noção de que os negros são piores do que os brancos, em termos estéticos, culturais e intelectuais (Paixão, 2008).

A união desses dois ingredientes transformou 0 mestiço em um patrimônio que tem uma dupla função, como se fosse uma carta curinga: a) durante quase todo o tempo essa carta permanece guardada e cumpre o papel silencioso (e aqui relembramos Foucault) de perpetuar os locais sociais solidamente estabelecidos e em desnível - a carta conserva em si os elementos estigmatizantes que fazem com que as hierarquias não sejam questionadas; b) em outros momentos, a carta é "sacada da manga" toda vez que a estabilidade racista for abalada com propostas tais como as ações afirmativas, e então ela é utilizada para sensibilizar a todos com o discurso confortante de que viveríamos "em harmonia". D ito de outra forma, o discurso da mestiçagem, em nosso entender, é um curinga no sentido em que ele é acionado conforme a conveniência: seja para aproximar e causar a ilusão de que somos harmoniosamente misturados, ou então para demarcar muros e manter as distâncias sociais.

Inter pretar a complexidade das relações raciais no Brasil e o novo desenho de interações que é criado pela adoção de ações afirmativas requer um esforço crescente de imaginação sociológica, em um contexto no qual asideias têm circulação transnacional e trazem questionamentos aos velhos paradigmas científicos e políticos das $\mathrm{C}$ iências Sociais ${ }^{15}$. A eficácia simbólica e societária do discurso da mestiçagem (que é o resultado social da noção biológica de miscigenação) cumpriu um papel histórico de estratificação social sem precedentes, em que pretos, pardos e indígenas encontram-se

14 Entre os argumentos levantados pelos estudantes, vemos que aqueles que trazem fundamentação em raça (grupo argumentativo B) são majoritariamente relacionados à noção de mestiçagem. Na UFPR, na UEL e na UFRGS, por exemplo, 100\% de todos os argumentos sobre raça sustentam como noção central a mestiçagem. No caso da UERJ, 57,14\% dos argumentos sobre raça tem esse fundamento, enquanto na UFBA, a miscigenação é o ponto central de 33,33\% de todos os argumentos do grupo argumentativo B. 15 Sobre esses deslocamentos no pensamento sociológico, ler Silvério (2003). 
em lugares sociais subalternizados, o que dificilmente poderia ser explicado unicamente por fatores econômicosis.

A análise dos argumentos sobre raça levantados pelos estudantes também possibilitou a verificação de contradições cometidas por eles ao criticarem os programas de ação afirmativa. Essas contradições ficam muito evidentes em três casos: um da U ER J (processo no 200.300.132.610 / R J), outro da U FR GS (processo no 2008.0400004125-6/R S) e outro da U FBA (mandado de segurança $s / n=/ B A$ ). Esses três alunos fizeram a crítica de que o Brasil é um país "mestiço" e que, portanto, seria impossível saber quem é negro e quem é branco e ao mesmo tempo, contestaram a auto- declaração de cor/raça pois, segundo eles, esse procedimento "abre espaço para fraudes". 0 ra, se não podemos identificar quem é negro ou branco, como pode existir o risco de alguém mentir sobre sua cor ou raça? $\mathrm{M}$ ais do que isso, quem pode julgar (e com quais parâmetros) se a declaração é verdadei ra ou falsa? N ão faz sentido falar em mentira ou fraude, visto que a identificação é por autodeclaração. Isso, por si só, já deveria encerrar qualquer polêmica.

0 princípio do mérito também foi bastante utilizado pelos estudantes e desembargadores nas ações judiciais analisadas ${ }^{17}$. Com relação ao vestibular da U ER J, por exemplo, esse princípio foi utilizado por $85,71 \%$ dos estudantes que acionaram a justiça. Esse princípio é observável nos casos da U ER J principalmente por falas do tipo: " se não fosse o sistema de reserva de vagas, eu (o aluno) passaria no vestibular, pois obtive nota suficiente". Percebe- se que os discursos conservadores nos quais o mérito é reiterado na sua formulação mais dura pressupõem que as vagas nas universidades têm donos e que as propostas para a entrada de jovens de escolas públicas, negros e indígenas viriam abalar essa estabilidade. 0 mesmo advogado citado anteriormente, que defende um aluno em ação judicial contrária à U FBA, ao falar sobre 0 direito à educação, presente nos Artigos 205 e 227 da CF/ 88, parece tomar como pressuposto que as ações afirmativas nas universidades retiram as vagas pertencentes a um determinado grupo social. Ele afirma que essas medidas são uma:

manifesta discriminação em relação aos estudantes de classe média oriundos da rede de ensino particular que não são considerados carentes, em relação aos quais inexiste razão de direito que autorize seu alijamento de algo que, por Lei thes pertence, na medida em que é custeada com dinheiro público. ( $M$ andado de segurança, s/n, BA, grifo nosso) $)^{18}$

O s princípios da igualdade e do mérito guiaram 0 processo de transição do antigo regime europeu para o Estado democrático moderno. Esses dois princípios foram construídos de forma interligada, de uma tal manei ra que a igualdade atua como ideia reguladora do mérito, oferecendo no decorrer da história os critérios para que este se perpetue. A ssim, esses fundamentos continuam a agir como mecanismos de regulação de instituições e legislações até os dias de hoje.

$\mathrm{N}$ a obra A economia das trocas simbólicas (2007), Pierre B ourdieu discute como o sistema de ensino oferece os mecanismos para a perpetuação de privilégios e hierarquias sociais, distribuindo o capital cultural de forma desigual entre os grupos sociais, o que não difere, em sua essência, dos mecanismos de clientelismo e parentesco do antigo regime. De acordo com ele,

Ao apresentar as hierarquias sociais e a reprodução destas hierarquias como se estivessem baseadas na hierarquia de 'dons', méritos ou competências que suas sanções estabelecem e consagram, ou melhor, ao con-

16 A ideia de que as disparidades sociais no Brasil são fruto de elementos econômicos, e não raciais, foi muito difundida pelo estudo intitulado Pretos e brancos na Bahia, publicado em 1942 por Donald Pierson, teórico da Escola de Chicago. Para ele, o fato de os negros estarem mais intensamente presentes entre os mais pobres, entre os menos escolarizados e entre as pessoas que exercem as profissões mais desvalorizadas e degradantes é fruto do recente passado escravista, um passado que é utilizado até hoje como justificativa e que nunca está distante o suficiente para reverter as disparidades. De um lado estava Gilberto Freyre, com Sobrados e mucambos (1936), e, de outro, a obra de Pierson: ambos sustentaram uma ideia básica de que o Brasil era livre do racismo, apresentando apenas casos isolados de preconceito, mas somente preconceito de cor, jamais de raça. Então, para eles, apesar da rigidez da sociedade patriarcal, a sociedade brasileira estaria sempre aberta para a ascensão social do negro, ou do mulato, para utilizar os termos freyrianos (Paixão, 2008).

17 No caso dos argumentos levantados pelos estudantes, o argumento do mérito (grupo argumentativo B, sobre raça) aparece fortemente relacionado com o argumento que defende a criação apenas de políticas universalistas (categorizado no grupo argumentativo C, sobre educação e sociedade). Já no caso dos desembargadores, estes utilizaram o argumento do mérito relacionado à noção de excelência acadêmica (grupo argumentativo $\mathrm{C}$, sobre educação e sociedade).

18 Nesse mesmo sentido, um procurador da república, responsável por uma ação que cancelou temporariamente o sistema de reserva de vagas da UFSC, deixou escapar em entrevista concedida ao jornal Zero Hora, em 25 de janeiro de 2008, a ilustrativa frase: "cota na vaga dos outros é refresco" (grifo nosso). O procurador temia que o TRF da $4^{a}$ região (Rio Grande do Sul, Santa Catarina e Paraná) derrubasse seu pedido de cancelamento da reserva de vagas na UFSC. Esse tribunal tem indeferido pedidos dessa natureza sob o argumento de que a implementação de ações afirmativas não necessita de lei específica e que se trata de medida compensatória pelo débito histórico com os negros. Esperando que isso pudesse acontecer, e na intenção de provocar o tribunal, já estava preparando uma ação contra o próprio TRF 4 , que estava com um processo de seleção em andamento, o qual não estabelecia reserva de vagas para negros e indígenas. 
verter hierarquias sociais em hierarquias escolares, 0 sistema escolar cumpre uma função de legitimação cada vez mais necessária à perpetuação da 'ordem social' [...] os novos mecanismos culturais e escolares de transmissão viriam apenas reforçar ou substituir os mecanismos tradicionais, como por exemplo, a transmissão hereditária de um capital econômico, de um nome de família ou de legado de relações sociais. (Bourdieu, 2007, p. 311-312)

D essa forma, o argumento do mérito esconde em si dois problemas básicos: primeiro, porque questões que são de ordem social são transformadas em questões específicas do sistema educacional, no intuito de desviar o foco da cadeia de privilégios existente. $E$, em segundo lugar, o princípio do mérito é sustentado por uma imagem de igualdade de oportunidades e de procedimentos democráticos e, então, os sujeitos que são historicamente aprovados em um processo seletivo universitário comemoram, como se suas aprovações fossem imprevistas. Pelo contrário, a aprovação de alguns grupos sociais é tão previsível e certa que ouvimos frases como as do advogado que citamos acima, falando sobre as "vagas que lhe pertencem" (aos estudantes de classe média oriundos da rede de ensino particular). Sobre esse segundo problema do princípio do mérito, Bourdieu diz:

Os mecanismos objetivos que permitem às classes dominantes conservar o monopólio das instituições escolares de maior prestígio se escondem sob a roupagem de procedimentos de seleção inteiramente democráticos cujos critérios únicos seriam o mérito e 0 talento, e capazes de converter aos ideais do sistema os membros eliminados e os membros eleitos das classes dominadas, estes últimos os 'milagrosos' levados a viver como 'milagroso' um destino de exceção que constitui a melhor garantia da democracia escolar. (Bourdieu, 2007, p. 314)

Como citamos anteriormente, a defesa do princípio do mérito é intensificada com o argumento sobre excelência acadêmica, levantado por vários dos desembargadores aqui pesquisados ${ }^{19}$. A crença presente em suas falas é que, com a adoção de ações afirmativas, começam a ingressar na universidade estudantes "menos capacitados", "menos talentosos", o que colocaria em risco a qual idade educacional da instituição. 0 ra, a que qualidade os desembargadores estão se referindo? 0 que confere qualidade a uma IES é a restrição do acesso, possibilitando a entrada apenas daqueles pertencentes aos estratos sociais historicamente privilegiados?

Todo esse apelo ao princípio do mérito nos faz lembrar do clássico livro de ficção histórica T he rise of meritocracy, 1870 - 2033, escrito por M ichael Young em 1958, no qual ele reúne e mostra aqueles que ele considera ser os principais elementos em uma sociedade liberal meritocrática ideal. Essa sociedade seria pautada na ampla igualdade de oportunidades, aberta ao "talento individual" e, por isso mesmo, seria constantemente regida por mecanismos capazes de mensurar as habilidades, como os testes de inteligência, que classificam as "capacidades" e com isso demarcam as posições sociais que cada um deve ocupar. Essa sociedade, segundo Young, teria nascido após a queda da aristocracia patriarcal, clientelista e hereditária e se solidificou sobre as bases do que ele chamou de uma "aristocracia do talento" (Young, 1958; M oehlecke, 2004). C om a concretização do projeto meritocrático, as desigualdades sociais e econômicas já não podiam ser atribuídas ao contexto social, mas passaram a ser de responsabilidade individual. Só restava a cada pessoa se convencer de sua culpa. De acordo com Young:

A gora que as pesso as são classificadas por habilidade, a distância entre as classes inevitavelmente ampliou-se. $M$ as a classe alta não é mais refém de dúvidas sobre sua capacidade nem de autocriticismo. H oje os emergentes sabem que seu sucesso é apenas uma recompensa por sua própria capacidade, por seu próprio esforço e por seu inegável empenho. Eles merecem pertencer a uma classe superior. [...] H oje, a elite sabe que, exceto por um grave erro administrativo que deve ser corrigido assim que for descoberto, aqueles que the são inferiores socialmente também em outros aspectos isto é, em duas qualidades vitais, inteligência e educação. [...] H oje todas as pessoas, por mais humildes que sejam, sabem que tiveram todas as chances. Elas são testadas continuamente. [...] N ão são elas capazes de reconhecer que têm um status inferior - não como no passado, devido a uma oportunidade que Ihes tenha sido negada - mas porque são inferiores? Pela primeira vez na história humana o ser humano inferior não possui nenhuma desculpa para melhorar sua autoestima. (Young, 1958, p. 85-86)

Segundo Young, a principal instituição de apoio à "sociedade do talento" seria a escola, pois ela exerceria a importante função de selecionar os mais inteligentes dos menos, através dos seus mecanismos e testes de aptidão. N essa sociedade em que cada um é recompensado de acordo com suas "capacidades", o mérito também criaria um grande abismo entre atividades manuais e intelectuais:

N ós somos os pensadores, ele disse. N ão somos? Somos pagos para pensar. $B$ em, do que precisamos para realizar nosso trabal ho? [...] Precisamos de secretárias no trabal ho e empregados domésticos em casa - as tarefas para a sobrevivência tiram energia daqueles ta- 
lentosos que deveriam se dedicar a coisas superiores. A ssim como um carpinteiro precisa de um formão ou um mecânico precisa de uma chave inglesa, nós precisamos de livros para instruir, quadros para estimular e vinho para acalmar. $\mathrm{N}$ ão é por nós que pedimos. É pelo bem da sociedade, para a qual o serviço de nossos cérebros é dedicado. N enhum ciúme, vaidade, egoísmo devem ficar no caminho da realização humana e do progresso social. (Young, 1958, p. 126).

0 livro de Young não é apenas mais uma obra de ficção, pois ele retrata um projeto de sociedade liberal que orientou diversas políticas em muitos países capitalistas (M oehlecke, 2004). A pesar de ouvirmos cotidianamente que no Brasil as relações sociais ainda são fundamentadas pelo clientelismo e pela cultura do favor, ele seria um país al heio ao ideário meritocrático? Pelo menos no que se refere aos mecanismos de acesso ao ensino superior, e hoje com todos os debates jurídicos em torno das ações afirmativas, o Brasil apresenta muitos elementos em comum com a sociedade de Young.

M esmo entre os desembargadores que deram pareceres favoráveis aos programas de ação afirmativa analisados, existe 0 argumento de que "os programas de ação afirmativa nas universidades não são incompatíveis com a preservação da qualidade do ensino, uma vez que continuariam entrando pelo vestibular os alunos com as melhores pontuações" 20 . O s desembargadores também fazem a defesa das ações afirmativas com 0 argumento de que os estudantes que entraram com ações na justiça não seriam aprovados no vestibular independentemente das ações afirmativas, haja vista as pontuações que receberam. A utilização desse argumento nos mostra uma situação contraditória, pois, ao mesmo tempo em que ajudou para a continuidade dos programas de ação afirmativa, é uma defesa que não demonstra nada mais do que a simples obediência, por parte do operador de direito, da premissa do mérito. Logo, o princípio democrático-liberal do mérito individual continua sendo um dos pilares mais defendidos na justiça brasileira, tanto por contrários quanto por defensores das ações afirmativas.

0 que vemos, portanto, é uma série de vitórias conquistadas em meio a antigos problemas e a antigas construções de preconceito. Talvez estejamos em um terreno de transição, onde diferentes conceitos e visões de mundo se compartilham em conflito. U m espaço onde existem pessoas (tanto operadores do direito quanto quaisquer outras) que, a despeito das boas intenções, assinam sentenças favoráveis com as mesmas canetas usadas pelos que são contrários. E, dessa forma, conseguimos dar passos importantes, mas os paradigmas continuam os mesmos.

\section{Reflexões para além do discurso da diversidade}

Estas inquietações aqui discutidas também são voltadas para as C iências Sociaise a Sociologia em especial, que vive um momento bastante importante de reflexão consigo mesma, na busca de um contraponto crítico às concepções clássicas, tais como indivíduo, sujeito, identidade entre outros. $\mathrm{O}$ u seja, as antigas convicções estão em conflito, nada está dado. A emergência dos $E$ studos C ulturais e do pós-colonialismo ${ }^{21}$ dá ossinais desse cenário onde não há certezas, e essas são correntes que surgem a partir de problemáticas externasà academia, oriundas das profundas mudanças de meados do século $X X$ e dos chamados "novos coletivos", das novas demandas sociais, entre elas, o movimento negro, o movimento indígena, o movimento GLBTT, o movimento sem terra, enfim, uma gama imensa e completamente diversificada de demandas e narrativas descentralizadas. 0 momento que vivemos é de transição de uma sociedade na qual a representação monocultural construída e fixada pelas elites intelectuais e políticas está dividindo espaço com novas representações sociais, profundamente dinâmicas e multiculturais.

20 Este argumento é recorrente entre os desembargadores que deram pareceres favoráveis aos programas de ação afirmativa das universidades UERJ, UFPR, UFRGS e UFSC.

21 O surgimento dos Estudos Culturais é associado na maioria das vezes aos primeiros trabalhos de Stuart Hall, mas também inclui outros intelectuais tais como Richard Hoggart, Raymond Williams e E. P. Thompson. Juntos - e inclusive com a presença de Charles Taylor, que mais tarde se tornou referência da Teoria do Reconhecimento - eles fundaram no final dos anos 50 s e início dos 60 do século XX a Nova Esquerda Inglesa, pautada nas obras de Gramsci, vistas como alternativa teórica para as questões não respondidas pelo marxismo mais ortodoxo, tais como cultura, ideologia, linguagem e o simbólico (Hall, 2006). Nos anos 70, Stuart Hall foi diretor do Centre for Contemporary Cultural Studies (CCCS), fundado em 1964 e que se destacou pela preocupação política em estabelecer sólidas bases teóricas sobre cultura, que incluíam obras de fotojornalismo, programas de televisão e literatura (Liv Sovik in Hall, 2006). Em 1979, Hall se transfere para a Open University, uma IES na qual adultos participam de aulas à distância e de seminários intensivos, em uma época em que o acesso às universidades britânicas era bastante limitado ou recente. Os Estudos Pós-Coloniais formam uma das vertentes teóricas pertencentes aos Estudos Culturais e são representados por autores como Edward W. Said, Paul Gilroy, Stuart Hall e Homi Bhabha. A crítica pós-colonial desloca as categorias tradicionais de análise, tais como classe e trabalho, e introduz outros pontos de vista, tais como raça, sexualidade, linguagem, nacionalidade, entre outras (Preciado, 2007). O "pós" do pós-colonialismo se caracteriza não apenas pelo sentido cronológico, mas também pela proposta de reconfiguração do campo discursivo e, com isso, das relações hierárquicas. 
Todo o período após os vinte anos da aprovação da C onstituição de 1988 reflete uma transição sociopolítica de uma sociedade que antes se pensava como cordial e homogênea na mestiçagem para uma outra heterogênea e conflituosa. $E$ a questão de fundo apresentada para todos aqueles que pensam (pró ativamente) as políticas de ação afirmativa no Brasil é em que medida as lutas e as propostas pautadas no reconhecimento da diferenças culturais têm contribuído para recriar a ordem social, sob outras perspectivas que não aquelas limitadas pelo universal ismo e pela normatização. Essa é uma preocupação muito bem discutida por H omi B habha (2007) quando ele observa que precisamos rediscutir as categorias impostas pelo discurso colonial, mas não com um olhar normativo: no lugar disso, precisamos conquistar a liberdade de uma prática política aberta e sem as exigências assi milacionistas. É importante que façamos um exercício de revisão das propostas alternativas ao mito da democracia racial para observarmos até que ponto essas são vias que de fato quebram o discurso opressivo, ou se são uma reapropriação do universalismo diferencialista 22 , que essencializa e estereotipa as diferenças.

A diferença, tal como esboçada pelos Estudos PósColoniais, nada tem a ver com construções identitárias homogeneizadoras, nem a uma dada pertença simbólica a algum lugar de nascimento, moradia ou inserção social. Ela é uma categoria enunciatória, que não é domesticada ou aprisionada em fronteiras, mas sim algo impreviśvel, incerto e contingente. A diferença do pós-colonialismo refere-se ao termo différance, utilizado por Jacques Derrida, e que não é traduzível no processo de significação dos signos nem organizável nas polaridades de dominação modernas (preto/ branco; mulher/ homem; eu/ outro; nós/ eles, sujeito/ objeto). A incompletude dessas representações encontra-se fundamentada na própria linguagem, na complexa articulação (para usar uma terminologia de Stuart $\mathrm{H}$ all) entre discursos e sujeitos, que são construídos simultaneamente (C osta, 2006). A articulação entre discursos e sujeitos gera o que $\mathrm{H}$ all chamou de sujei- tos coletivos, que podem ser alvo da principal estratégia discursiva da diferença: o estereótipo.

0 estereótipo, de acordo com Bhabha, tem natureza dúbia, pois é algo estático (que está sempre no lugar) e, ao mesmo tempo, que deve ser ansiosamente repetido (Bhabha, 2007). É com a problematização do discurso do estereótipo e dos processos de subjetivação que Bhabha percebe o caminho a ser seguido na compreensão e quebra das categorias hegemônicas. A crítica ao discurso do estereótipo se estende também ao modo como se construiu o valor da diversidade, que historicamente foi aceita porque está dentro dos arranjos normativos eurocêntricos, reduzindo as particularidades do diverso ao exotismo e à folclorização.

A substituição da noção de diversidade pela noção ressignificada da diferença é, mais do que uma questão de escolha conceitual, algo que se reflete na vida prática, nas escol has e nos perfis das políticas públicas. Trocando em miúdos com o objeto de estudo da pesquisa realizada, se a diferença fosse compreendida como algo não fixo, ficaria mais evidente tanto para estudantes quanto para desembargadores que as ações afirmativas têm um papel muito mais amplo do que eles demonstram entender em suas falas. Ao discutirmos as ações afirmativas no Brasil, não falamos simplesmente em realocação de posições, mas em mudança de paradigmas e no questionamento dos processos de subjetivação e de sujeição pelos quais muitos passam devido à cristalização das hierarquias causada pela manutenção do discurso da mestiçagem.

Vemos, então, que as discussões sobre constitucionalidade das ações afirmativas continuam sendo importantes no Brasil - até porque há muitas barreiras conservadoras a serem quebradas - mas, elas são importantes não para ficarmos na conformidade igualitária da C onstituição, mas para ultrapassarmos suas fronteiras. A implementação das ações afirmativas é um processo que ainda se encontra no início em nosso país, mas a concentração de muitos esforços e a queda de várias barreiras, inclusive no campo jurídico, indicam que esse é um processo já irreversível.

\section{Referências}

A BR EU, Sérgio. Igualdade. A afirmação de um princípio jurídico inclusivo. In: FER ES Jr., João; ZO N I N SEI N , Jonas (O rgs). A ção afirmativa no ensino superior brasileiro. Belo H orizonte/ R io de Janeiro: Ed. U FM G/luperj, 2008.

BH A BH A, H omi K. O local da cultura. B elo H orizonte: Ed. U FM G, 2007.

BO BBIO , N orberto. I gualdade e liberdade. 2 ed. R io de Janeiro: Ediouro, 1997.
. 0 positivismo jurídico: lições de filosofia do direito.

São Paulo: Ícone, 2006.

BO U R DIEU, Pierre. A economia das trocas simbólicas. São Paulo: Perspectiva, 2007.

BRUNI, José Carlos. Foucault: o silêncio dos sujeitos. Tempo Social - R evista de Sociologia da U SP, vol. 1, p. 199-207, 1989.

CÉSA R, R aquel Lenz. A cesso à justiça para minorias raciais 
no B rasil: é a ação afirmativa o melhor caminho? $\mathrm{R}$ iscos e acertos no caso da UERJ. R io de Janeiro, 2004. Tese (D outorado em Direito) - U niversidade do Estado do R io de Janeiro.

C O STA, Sérgio. A construção sociológica da raça no Brasil. E studos A fro-A siáticos, v. 24, n. 1, p. 3-61, 2002.

D ois A tlânticos: teoria social, anti-racismo, cosmopolitismo. Belo Horizonte: Ed. U FM G, 2006.

FOU CAU LT, M ichel. V igiar e punir. 31 ed. Petrópolis: Editora Vozes, 2005.

FER ES Jr., João; ZON IN SEIN , Jonas. A consolidação da ação afirmativa no ensino superior brasileiro. In:

(0 rgs). A ção afirmativa no ensino superior brasileiro.

Belo H orizonte/ R io de Janeiro: Ed. U FM G/luperj, 2008.

FER ES Jr., João. A spectos normativose legais das políticas de ação afirmativa. In: CONFER ÊNCIA INTER NACIONAL DA R EDE DE ESTUDOS DE AÇÃO AFIR MATIVA, 1, 2005, $R$ io de Janeiro.

; SILVA, Luiz Fernando M artins da. Ação afirmativa. In: BAR R ETO, Vicente de Paulo (Coord.). D icionário de filosofia do direito. São L eopoldo, R S/ R io de Janeiro: Ed. Unisinos/ R enovar, 2006.

GUIM AR ÃES, A ntônio Sérgio. N acionalidade e novas identidades raciais no Brasil: uma hipótese de trabalho. In: So U Z A, Jessé (O rg.). D emocracia hoje: novos desafios para a teoria democrática contemporânea. Brasília, 2001.

. 0 acesso de negros às universidades públicas. In: SILVA, Petronilha B. G.; SILVÉR IO, Valter R. (O rgs.). E ducação e ações afirmativas: entre a injustiça si mbólica e a injustiça econômica. Braślila: Instituto $\mathrm{N}$ acional de Estudos e Pesquisas Educacionais A nísio Teixeira, 2003.

2002. Classes, raças e democracia. São Paulo: Ed. 34,

H A LL, Stuart. D a diáspora: identidades e mediações culturais. Belo Horizonte: Ed. U FM G, 2003.

A identidade cultural na pós-modernidade. 11 ed. $R$ io de Janeiro: DP\&A 2006.

HER INGER, R osana. Políticas de promoção da igualdade racial no Brasil: um balanço do período 2001-2004. In: WORKSHOP DA REDE DE ESTUDOS DE AÇÃO AFIR M ATIVA, 1, 2005, $R$ io de Janeiro.

IPEA. B rasil: o estado da nação. Braśl lia: IPEA, 2006.

M EDEIR O S, Priscila M artins. R aça e E stado democrático: 0 debate sociojurídico acerca das políticas de ação afirmativa no Brasil. São Carlos, 2009. D issertação (M estrado em Sociologia) - U niversidade Federal de São Carlos.

. $R$ aça e ações afirmativas: releituras sociojurídicas no contexto de pós-modernidade. In: BO LA M A, N ico A. (O rg). A s imagens das $C$ iências Sociais no B rasil: novos olhares sobre a sociedade contemporânea. São C arlos: Pedro e João Editores, 2008.

M ISKO LCI, R ichard. A teoria queer e a Sociologia: o desafio de uma analítica da normalização. Sociologias, v. 11, n.
21, p. 150-182, 2009.

M O EH LECK E, Sabrina. A ção afirmativa: históriae debates no Brasil. C adernos de Pesquisa, no 117, p. 197-217, 2002.

. F ronteiras da igualdade no ensino superior: excelência e justiça social. São Paulo, 2004. Tese (D outorado em Educação) - U niversidade de São Paulo.

M OOR E W EDDER BU R N , Carlos. Do marco histórico das políticas de ação afirmativa. Gênese das políticas de ações afirmativas e questões afins. In: SA N T O S, Sales A. (O rg.). A ções afirmativas e combate ao racismo nas A méricas. Braślia: M inistério da Educação/ U nesco, 2005.

N ETO, Cláudio Pereira de Souza. A constitucionalidade das cotas étnicas e sociais nas universidades brasileiras. Jurisprudência e parâmetros de decisão. In: FER ES Jr., João; ZO N IN SEIN, Jonas (O rgs). A ção afirmativa no ensino superior brasileiro. Belo Horizonte/ R io de Janeiro: Ed. U FM G/ Iuperj, 2008.

PAIX ÃO, M arcelo. A santa aliança. Estudo sobre o consenso crítico àspolíticas de promoção da equidade racial no Brasil. In: FER ES Jr., João; ZO N IN SEIN , Jonas (O rgs). A ção afirmativa no ensino superior brasileiro. Belo Horizonte/ $R$ io de Janeiro: Ed. U FM G/luperj, 2008.

PR ECIADO, B eatriz. Entrevista a Jesús C arrillo. C adernos Pagu, v. 21, p. 211-218, 2007.

Q U EIR OZ, D elcele M ascarenhas; SA N T O S, Jocélio Teles dos. Sistema de cotas: um debate. D os dadosà manutenção de privilégiose de poder. R evista E ducação e Sociedade, v. 27, n. 96, p. 717-737, 2006.

R ELATÓRIO DO COMITÊ NACIONAL I - II CON FER ÊNCIA MUNDIAL CONTRA O RACISMO, DISCR IM IN AÇÃO R ACIAL, XENOFOBIA E INTO LER ÂN CIA COR R ELATA. Brasília, 2001.

R O DR IGU ES, Tatiane Cosentino. M ovimento negro no cenário brasileiro: embates e contribuições à política educacional nas décadas de 1980-1990. São C arlos, 2005. D issertação (M estrado em C iências Sociais) - U niversidade Federal de São Carlos.

SAN TOS, Boaventura S. A construção multicultural da igualdade e da diferença. Palestra proferida no VII Congresso B rasileiro de Sociologia. R io de Janeiro, 1995.

SILVÉR IO, Valter R oberto. A (re)configuração do nacional e a questão da diversidade. In: ABR AMOW ICZ, A nete; SILVÉR IO, Valter R . (O rgs). A firmando diferenças: montando o quebra- cabeça da diversidade na escola. C ampinas: Papirus, 2005.

0 papel das ações afirmativas em contextos racializados: algumas anotações sobre o debate brasileiro. In: SILVA, Petronilha B. G; SILVÉR IO, Valter R. (O rgs.). E ducação e ações afirmativas: entre a injustiça simbólica e a injustiça econômica. Braślia: IN EP, 2003.

YOUNG, M ichael. T he rise of meritocracy, 1870-2033: an essay on education and equality. London: Thames and H udson, 1958. 


\title{
Contexts and significations of affirmative actions in the brazilian system of higher education: socio-juridical aspects and the deconstruction of the pact of silence
}

\begin{abstract}
The new scenario which was inaugurated with the first experiences of affirmative action policies in the Brazilian system of higher education has put forth a number of juridical disputes between the State, higher education institutions and individuals who felt at a loss because of such policies; in addition, it placed in the center of the national agenda the possibility of a revision of the democraticliberal principles and the mechanisms of social justice used in the country. W ith this in sight, we carried out research aimed at offering a sociological analysis of the repercussions, in the Brazilian juridical field, by the adoption of A ffirmative Actions in higher education geared mainly towards the black population. 0 ur aim was to we become aware of the representations of the society which are present in the discourses and the positioning of the Judiciary Power and of part of the students who sought the justice system to fight these measures. The primary sources of research were the resolutions made avai lable in the sites of the R egional and State Justice Tribunals, legal instruments and some interviews. The defense of race-mixing as a founding element of equality among subjects and the value of individual merit are some of the points which characterize these discourses analyzed in this article.
\end{abstract}

Keywords: affirmative action; universities; juridical Field; equality; merit.

\section{Contextos y significados de las acciones afirmativas en la enseñanza superior brasileña: los aspectos sociojurídicos y la desconstrucción del pacto de silencio}

\section{Resumen}

EI nuevo escenario inaugurado con las primeras experiencias de políticas de acción afirmativa en la enseñanza superior brasileña ha traído una serie de disputas jurídicas entre el Estado, las instituciones de Enseñanza Superior y los individuosque se sintieron engañados por tales políticas, además de poner en el centro de la agenda nacional la posibilidad de una revisión de los principios democráticoliberales y de los mecanismos de justicia social utilizados en el país. Frente a eso, realizamosuna pesquisa que tuvo como objetivo ofrecer un análisis sociológico de las repercusiones en el campo jurídico brasileño de la adopción de A cciones Afirmativas en la enseñanza superior, que se vuelven principalmente para la población negra, a fin de que percibamos las representaciones de sociedad presentes en los discursos y en los posicionamientos del Poder Judiciario y de parte de los estudiantes que accionaron la justicia contra esas medidas. Se constituyeron en fuentes primarias de pesquisa las sentencias disponibles en los sitios de los T ribunales de Justicia R egionales y Estatales, instrumentos legales y algunas entrevistas. La defesa del mestizaje como un elemento fundador de la igualdad entre los sujetos y el valor del merito individual son algunos de los puntos que caracterizan los discursos aquí analizados.

Palabras clave: acciones afirmativas; universidades; campo jurídico; igualdad; mérito. 